\title{
Short Paper \\ Development of an Accounting Information System with Data Migration for Company ABC
}

\author{
Javi Angela De Gorostiza \\ University of Asia and the Pacific \\ javi.degorostiza@uap.asia \\ Nur Aidil Bin Nordin \\ University of Asia and the Pacific \\ nuraidilbin.nordin@uap.asia \\ Xin Yi Pang \\ University of Asia and the Pacific \\ pang.xinyi@uap.asia \\ Mark Anthony Sabili \\ University of Asia and the Pacific \\ markanthony.sabili@uap.asia \\ (corresponding author) \\ Giuseppe Ng \\ University of Asia and the Pacific \\ giuseppe.ng@uap.asia \\ Sol Marian Mariano \\ University of Asia and the Pacific \\ solmarian.mariano@uap.asia
}

Date received: October 8, 2017

Date received in revised form: January 13, 2018

Date accepted: January 14, 2018

Recommended citation:

De Gorostiza, J. A., Nordin, N. A., Pang, X. Y., Sabili, M. A., Ng, G., \& Mariano, S. M. (2017). Development of an accounting information system with data migration for Company ABC. International Journal of Computing Sciences Research, 1(3), 50-64. doi: 10.25147/ijcsr.2017.001.1.15.*

*This paper is presented at the 2017 1st International Conference on Redesigning, Re-engineering Academic Direction for Global Competitiveness. 


\section{Abstract}

Purpose - The researchers intend to help Company $A B C$ in managing their financial transactions through developing an Accounting Information System (AIS) that would collect, store, and process financial transactions. This system would serve as an instrument needed in the creation of consolidated financial reports for Company $A B C$, such as Income Statement, Balance Sheet, and Invoices.

Method - The methodology for the system development follows Agile methodology. Deliverables would be presented to the client after every sprint to customize the AIS for Company $\mathrm{ABC}$.

Results - The Accounting Information System helps the accountants and stakeholders in their decision making process, in enhancing the quality of the financial reports, and in the auditing of financial transactions of the company.

Conclusion - With the help of the proposed system, accountants will no longer have a difficult time in creating their reports manually; hence, the proposed system shall help the stakeholders of the company to make sound decisions for the company.

Recommendations - To improve its accessibility to its users, it is also recommended that a mobile version of the system that works both in Android and iOS platforms be developed.

Research Implications - The use of AIS enables ABC company to collect, store, and process financial transactions into financial reports so as to aid in the decision making and the planning process of the company. However, the implementation of AIS is not an end in itself but rather, a possible important supporting arm to achieve commercial objectives.

Keywords - accounting, Accounting Information System, agile methodology, data migration, reports articles

\section{INTRODUCTION}

Company $A B C$ relies on a spreadsheet software for all their financial transactions. Although using spreadsheet software is helpful, it is not a long-term solution. Setting up the spreadsheet itself takes a lot of time. Using spreadsheet requires the user to have knowledge in the Accounting field. With this, the researchers intend to help Company $A B C$ in tracking their financial transactions through developing an Accounting Information System (AIS) that would eliminate manual transactions. This system would help in the consolidation of financial reports needed by Company $A B C$, such as Income Statement, Balance Sheet, and Invoices. People involved could request reports according 
to their needs. Additionally, this AIS allows their existing data to be migrated in the system to deliver accurate data for the reports to be requested.

The implementation of this AIS would aid in reducing incorrect business decisions since stakeholders and other concerned people would be given an opportunity to have a clear view of the company's financial position beforehand. This also allows users to generate reports on demand instead of waiting until the month's end cut off before creating these reports. Lastly, the AIS reduces inaccuracy that is possibly caused by the use of a spreadsheet software.

\section{Research Objectives}

The main objective of this research is to develop a system that will help manage and track the company's financial transactions through an Accounting Information System with Data Migration. Company ABC should be able to efficiently generate reports needed to meet corporate and management requirements from their accounting department. It has the following features:

1) Easy to generate reports. The system can generate invoices, income statements, and balance sheets.

2) Automated calculations. The system can generate reports with reliable calculation with the help of the generally accepted accounting principles.

3) User-friendly interface. The system can be used with ease through the easy to understand interface.

4) Hassle-free Data Migration. The system can accept data from old spreadsheet files to the system's database.

\section{REVIEW OF RELATED LITERATURE}

\section{Accounting Information System}

Today, a significant number of companies use information technology to deliver information and services to their customers. Systems serve people in their day-to-day activities by granting access to a wide range of information that interests them. People can also access significant information in systems (Del Rosario, Del Rosario, Nieva, Tan, \& Tangkeko, 2016). The ongoing revolution in information technology has had a significant influence on accounting information system (AIS).

Accounting information systems stand at the intersection of two disciplines namely accounting and information systems. Thus, the study of AIS is often viewed as the study of computerized accounting system (Weygandt, Kieso, \& Kimmel, 2012). They are conceptualized as a set of components that collect accounting data, store it for future uses, and process it for end users. Furthermore, AIS is considered as the computer-based 
systems that process financial information. The systems support decision tasks in the context of organization and regulation of financial activities (Diavastis et al., 2016).

The primary objective of an AIS is to gather and record data concerning events that have an economic impact on organizations. Furthermore, it involves the maintenance, processing and communication of information to internal and external stakeholders. It is a pre-eminently user-oriented system. It is also a collection of data and processing procedures that produces needed information for its users (Salehi, Rostami, \& Mogadam, 2010). Therefore, the use of AIS enables ABC company to record wide range of financial transactions assist in decision making and planning process in the company.

\section{Computerized Accounting System vs. Manual Accounting System}

There are two types of accounting systems and these are the manual accounting system and the computerized accounting system. The similarities of these two accounting systems are that they both use the same process, concept and accounting principles in operation. However, the differences of these two accounting systems include speed of information delivery, cost effectiveness, and efficient process of recording (Abdulialil \& Zainuddin, 2010). Unlike the manual accounting system, the computerized accounting system requires shorter period to provide accurate and useful information to the users because it helps the company to process all the business processes by automating and integrating all the business operations and transactions. Computerized accounting can handle large amounts of financial transactions accurately. After processing those financial transactions, the computerized accounting system can generate all the needed documents and reports automatically, access important information easily, and have better visibility into the daily business operation for the user (Wang \& Huynh, 2013).

\section{Importance of Accounting Information System}

AIS is important in decision making because the quality of the information given by financial reports will affect the decision making of the company. Stakeholders of the company need the high-quality information for the success of the company. High quality accounting information needs to fulfill four principal qualitative characteristics: comprehensibility, relevance, reliability, and compatibility (Spătărelu \& Petec, 2015). AIS helps the stakeholders in decision making process with internal controls, enhances the quality of the financial reports, and facilitates the financial transactions of the company (Mndzebele, 2013). Thus, AIS should generate reliable and relevant output for the company. Furthermore, AIS adoption is recommended because it can improve the firmlevel performance of a business (Tang, 2015). Increased competition in the market created the need for companies to invest in different accounting information systems. This is heavily attributed to globalization and technological innovations. This will also 
result in meeting the ever changing needs of businesses and in improving current operations. Studies also show that the key benefits of using AIS are better transactions, adaptivity to varying conditions, and a higher degree of competitiveness (Grande, Estebanez, \& Colomina, 2011).

However, users should not heavily depend on AIS. AIS can still be inadequate and has several deficiencies that the company must be able to address (Akkermans, Bogerd, Yücesan, \& Van Wassenhove, 2003). The nature of the company would affect the usage of the computerized accounting information system (Wang \& Huynh, 2013). This shows that the implementation of AIS is not an end in itself but rather, a possible important support to achieve commercial objectives.

\section{METHODOLOGY}

Agile Software Development is a methodology that anticipates the need for flexibility and applies a level of pragmatism into the delivery of the finished product (TechTarget, 2017). Theoretically, customers and the software development team would see eye to eye and communication would be necessary. However, the agile software methodology was formulated based on the agile manifesto and a set of twelve principles that aims to address this issue realistically (Kendall \& Kendall, 2011). The emphasis of the Agile manifesto is to focus the developers on the working conditions of the developers, the working software, the customers, and addressing changing requirements instead of focusing on the detailed systems development process, tools, all-inclusive documentation, legal contracts and detailed plans (Tegarden, Wixom, \& Dennis, 2013).

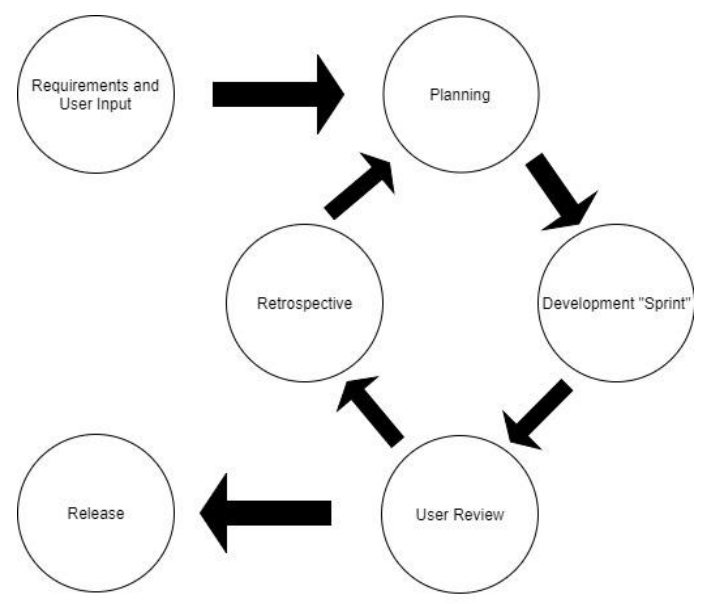

Figure 1. Agile Software Development

The methodology to be used for the system development follows an incremental approach. The researchers use the Agile software development where the developers start off with a project design, and then begin to work on the different features of the system. The work on these features is done in monthly sprints, and at the end of each 
sprint, deliverables are evaluated, and tests are presented to the company. The use of these sprints will allow developers to customize the software based on the needs of the Company $A B C$. Also, it would aid developers in discovering vulnerabilities and bugs. Figure 1 shows the Agile Software Development Process.

\section{Project Design and Implementation}

The proposed Accounting Information System for Company $A B C$ is a transaction processing application that would generate financial reports based on user's requests. The system can be accessed through any of the computer's web browser within the client's site. The system is to be used by the Company ABC Director, Head Accountant, Accountants, and Stakeholders as shown in the Software Context Diagram in Figure 2. The AIS can only be accessed by authorized users. Privileges may be given to administrators, accountants, and stakeholders. The system is exclusively designed for the use of the company itself. There are no other external organizations and systems that interact with it. The proposed system uses the programming languages Java and HTML following the MVC framework. The database of this system is MySQL. Moreover, Apache Tomcat 8 is the server for this system. The chosen IDE for the implementation of this system is NetBeans.

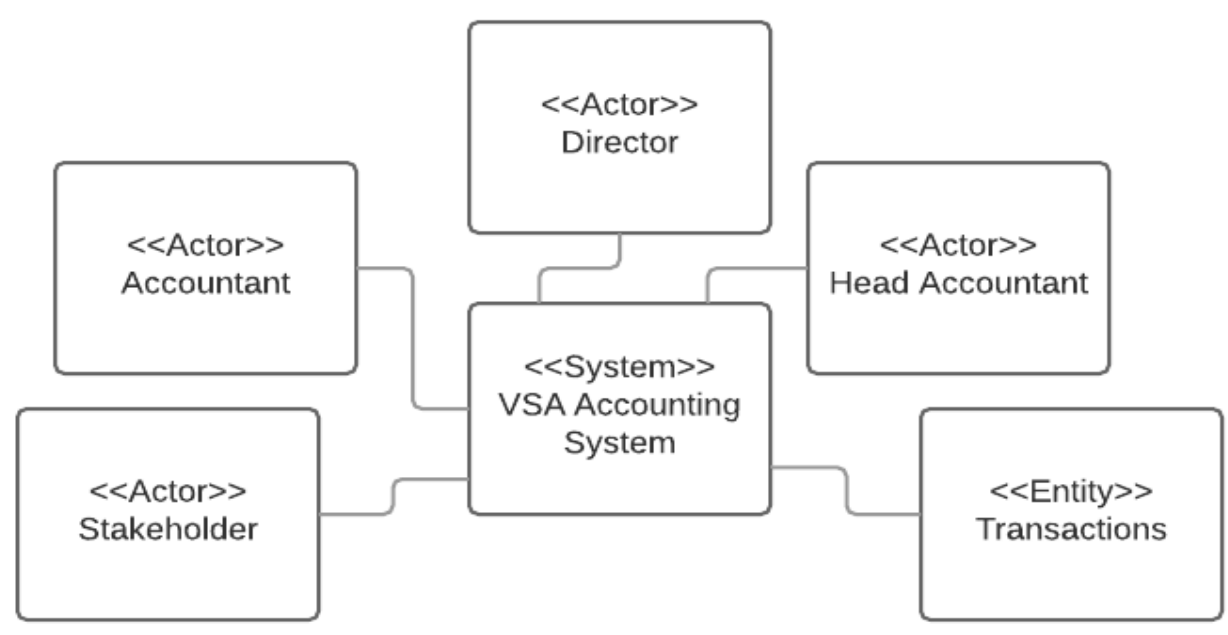

Figure 2. Software Context Diagram

\section{System Architecture}

Figure 3 shows the Architectural Diagram, which illustrates how the system is implemented, including the database, software, files, and people involved. The process represents programs, program modules, and manual procedures. The diagram shows that the system checks whether the user is an authorized personnel found in the user database. The authorized users can login using their credentials. When the user is authorized, he may utilize the system. 
Functions that can be done are based on the permission granted to each user profile. The stakeholder can view previously generated reports such as balance sheet and income statement. The accountant can add and update financial transactions. He can also generate financial reports. The administrator can perform the functions mentioned. Furthermore, he is the only authorized personnel to verify created and updated transactions and reports. He can add and update authorized users, list of banks, types of payment, charts of accounts, and company details.

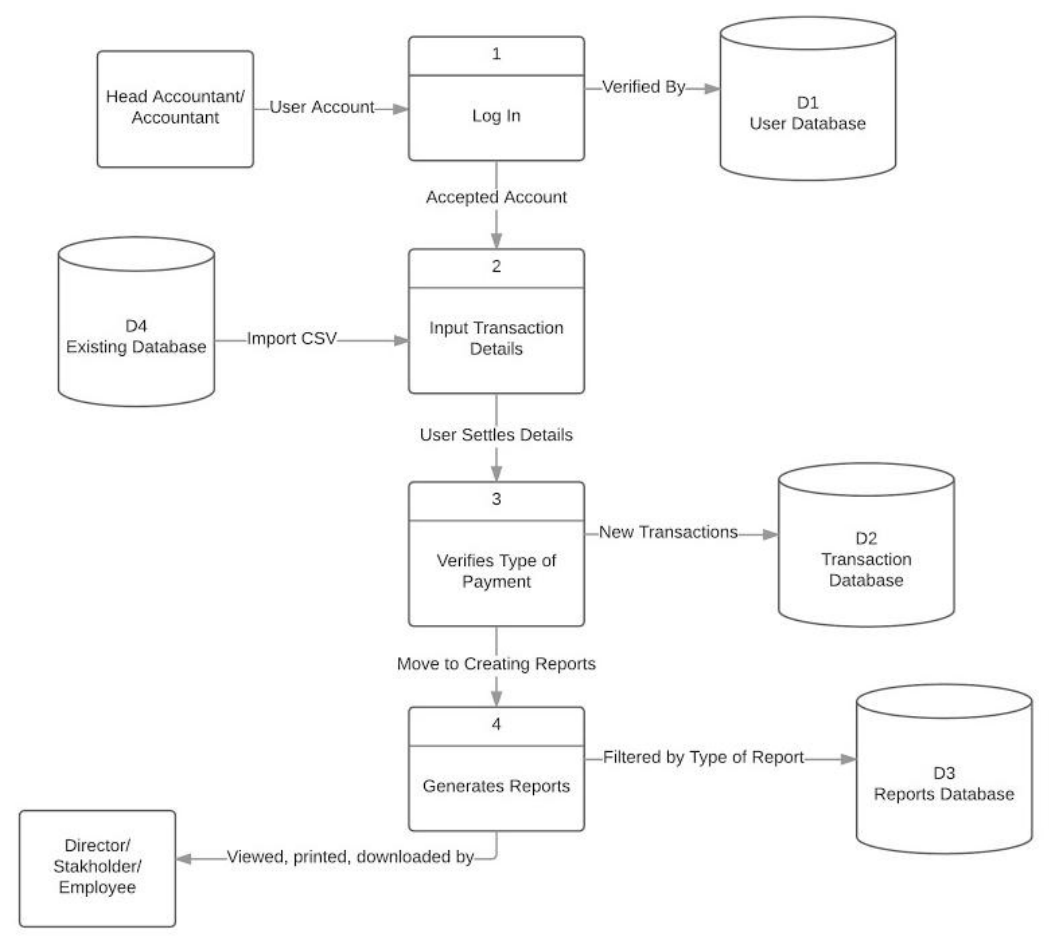

Figure 3. Architectural Diagram

\section{Dynamic Model for User: Log in}

The diagram below shows the sequence of how the user can log in into the system. The user gives the needed credential, namely: username and password, to login to the system. The credential is being verified by the system. If the user gives the correct username and password, the user is redirected to different page based on the privilege. Head Accountant is redirected to the Admin Page; Accountants are redirected to the Accountant Page; Employees are redirected to the Employee Page; Owner is redirected to the Admin Page. If the user gives the wrong username or password, the user is redirected to the login page, and the system shows an error message. 


\section{Dynamic Model for User: Create User}

As shown in Figure 5, the Head Accountant supplies the required information for the creation of a new authorized user such as employee ID, first name, last name, permission, and password. When a new authorized user is created successfully, the create user page displays a success message. If the Head Accountant inserted invalid information, the system redirects the Head Accountant to the create user page, and displays error message.

\section{Entity Relationship Diagram}

Figure 6 shows the Entity Relationship Diagram of the proposed system. A user can only have one account with permission that is granted by the Head Accountant. A user can view many reports. There are three types of reports such as balance sheets, income statements, and invoices. Balance sheet contains the total liabilities, total assets and total owner equity of the company. Income statement has the total revenue, total expenses, and new of income of the company. Head Accountants and Accountants can insert one or many transactions into the system. Each transaction can be either settled by one type of payment or different types of payments. There are three kinds of payment methods and these are credit card, cash, and cheque. Each report has at least one transaction.

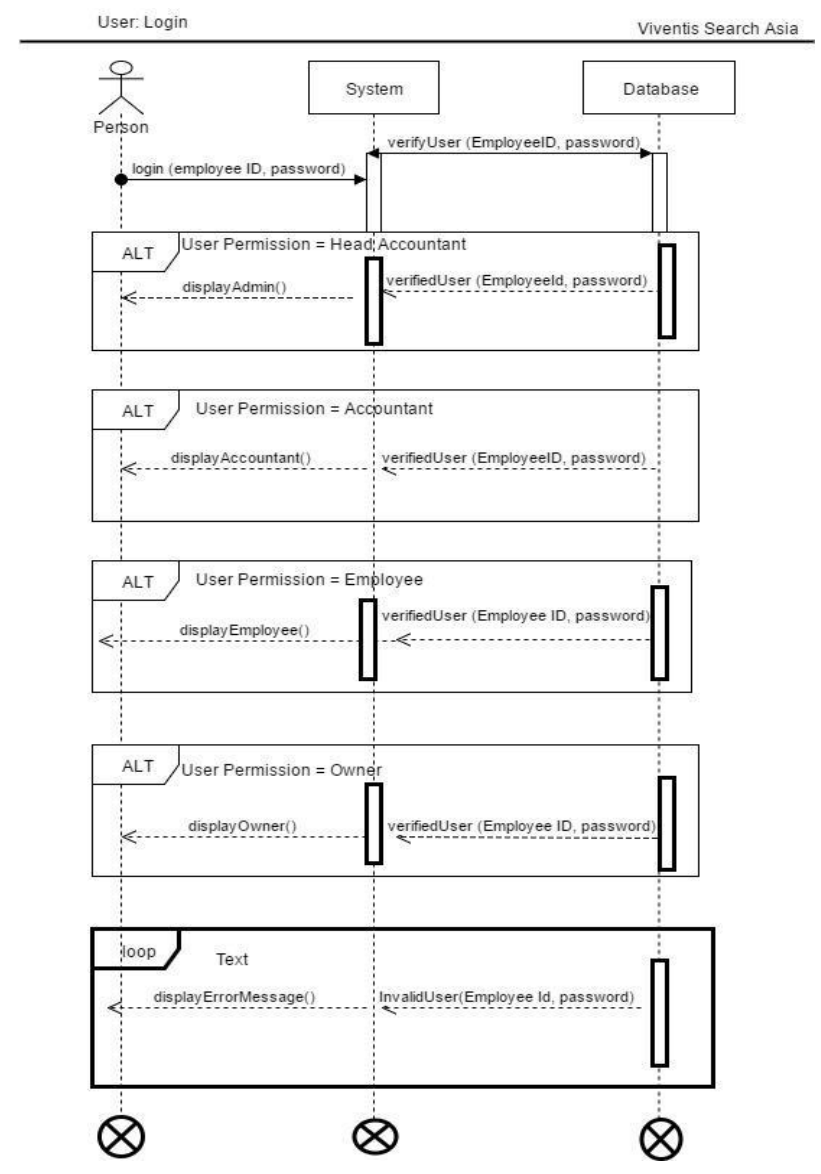


Figure 4. Sequence Diagram: User: Login

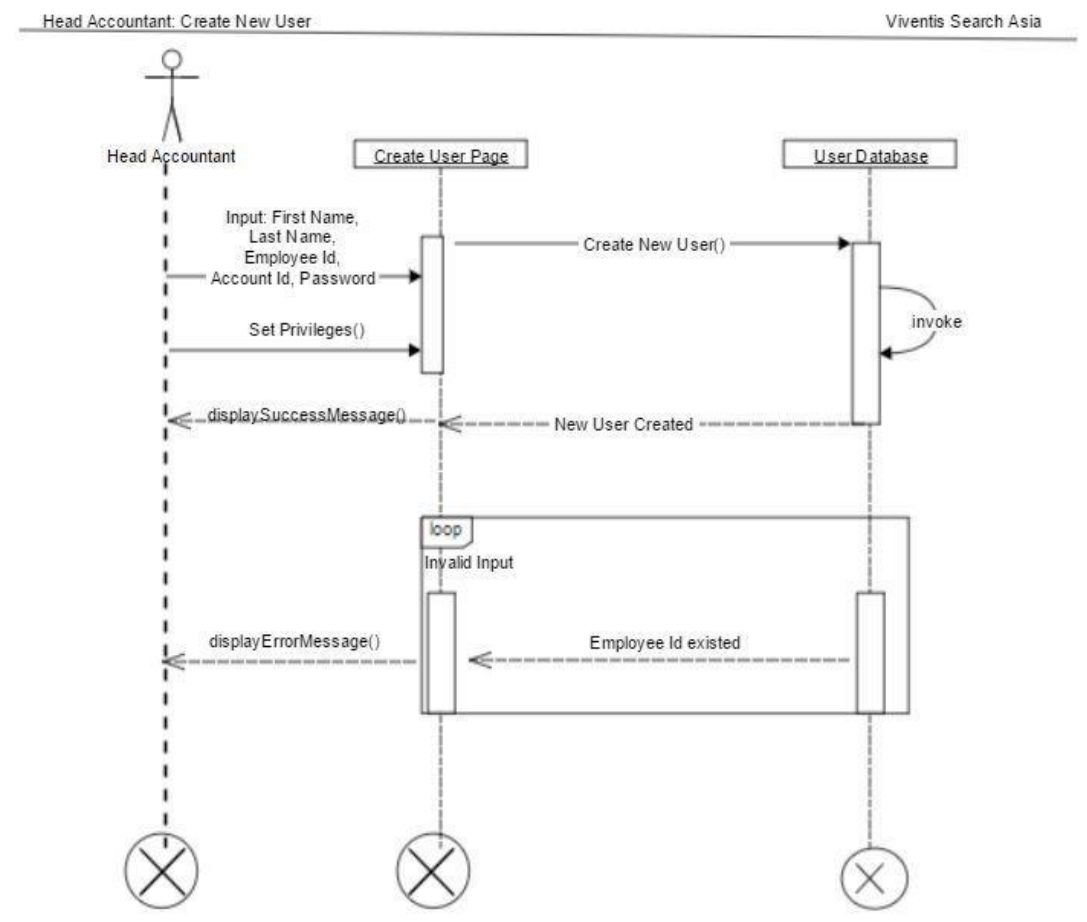

Figure 5. Sequence Diagram: User: Create User

\section{Data Flow Diagram}

Figure 7 shows the Data Flow Diagram for Input Transaction. Both Head Accountant and Accountants are authorized to enter the financial transactions into the system. Accountants provide the details of the transactions such as date of transaction, chart of accounts, bank details, credit amount, debit amount, and total amount of the transaction. After entering the details of the transaction, accountants choose the type of payment for the transaction. Then, the transaction record is being processed into the transaction database.

Moreover, both Head Accountant and Accountants are authorized to generate reports from the system. As shown in Figure 8, the Accountants choose the type of report which is needed by the company. Then, they choose the required transactions for making the report from the transaction database. The generated report is being saved in the report database. 


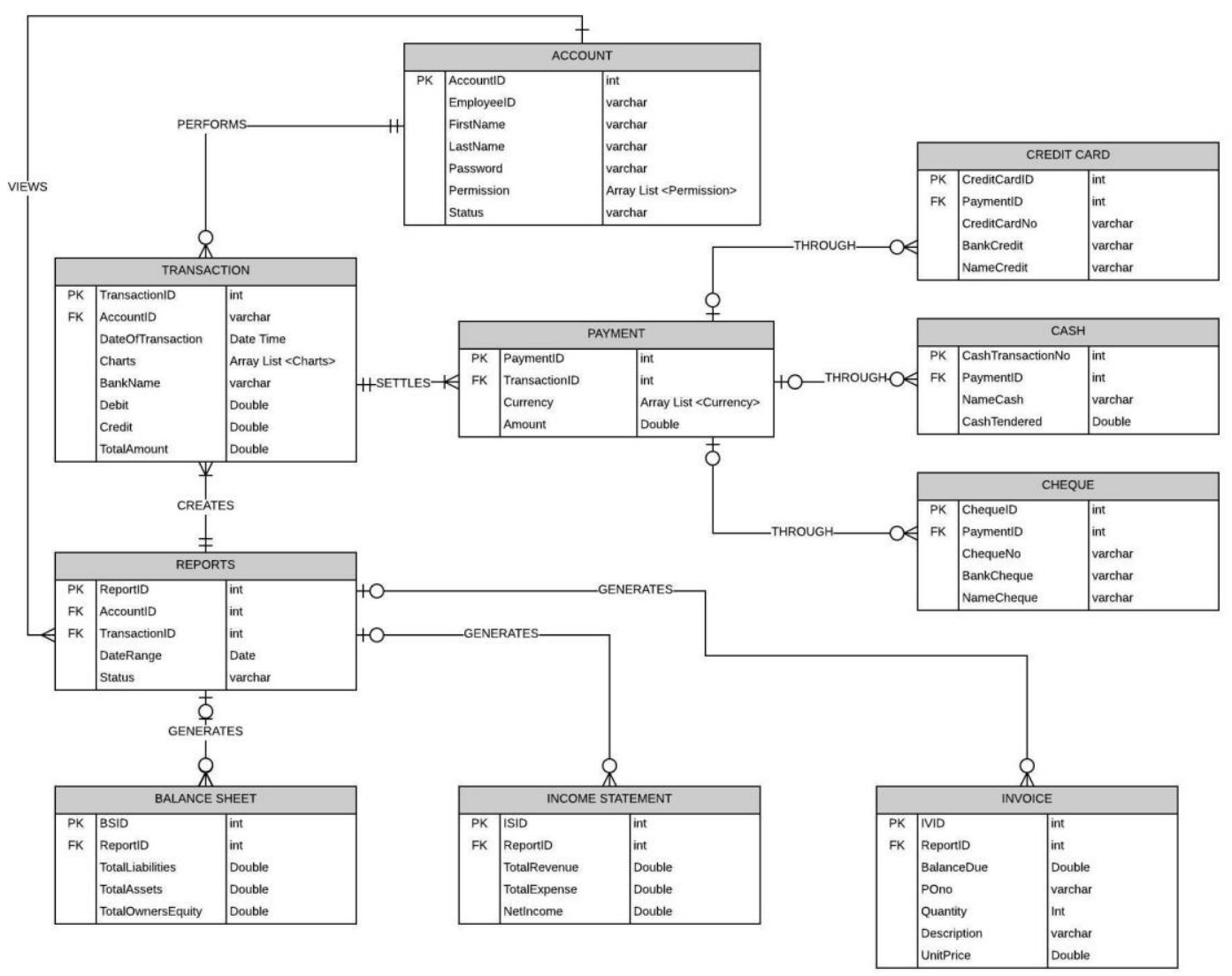

Figure 6. Entity Relationship Diagram

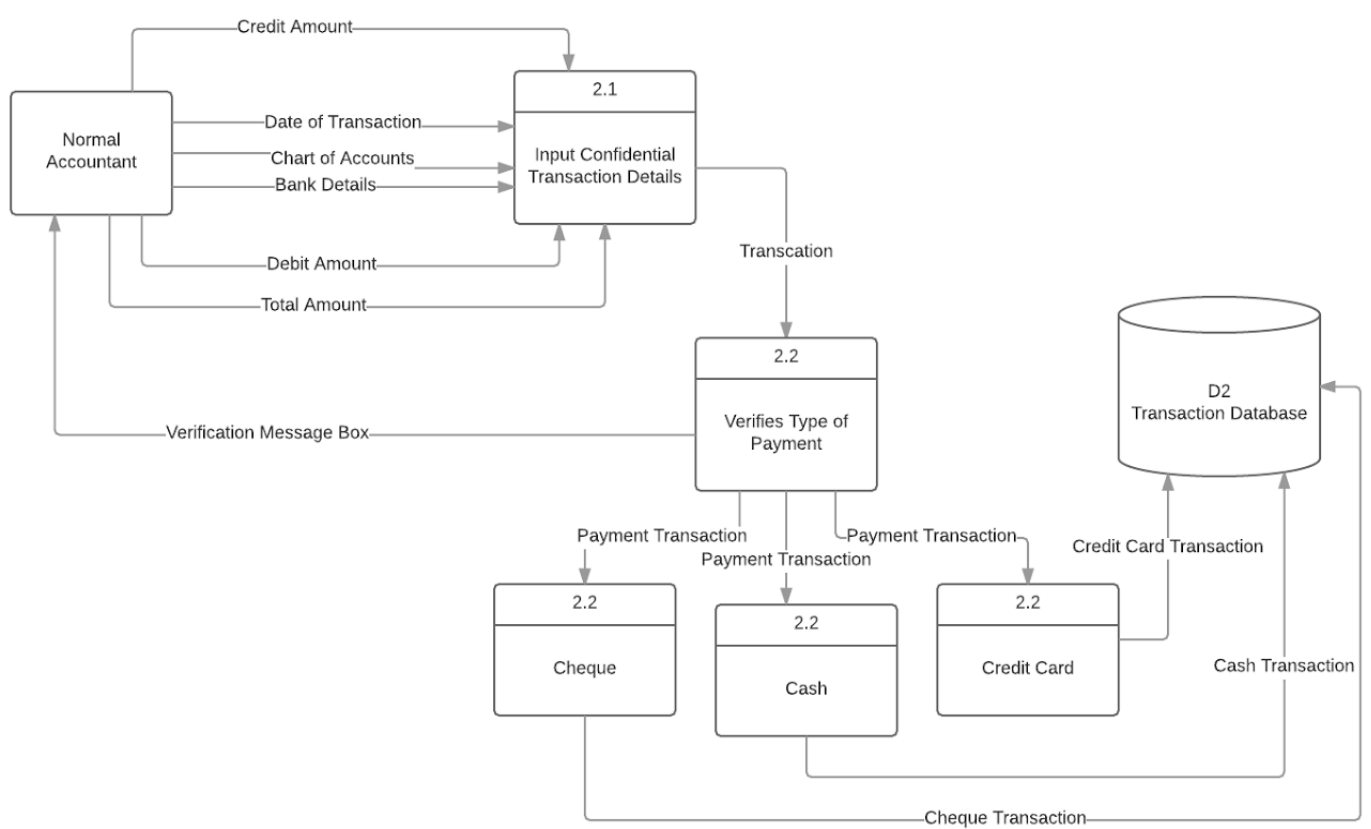

Figure 7. Data Flow Diagram: Level 1 - Input Transaction 


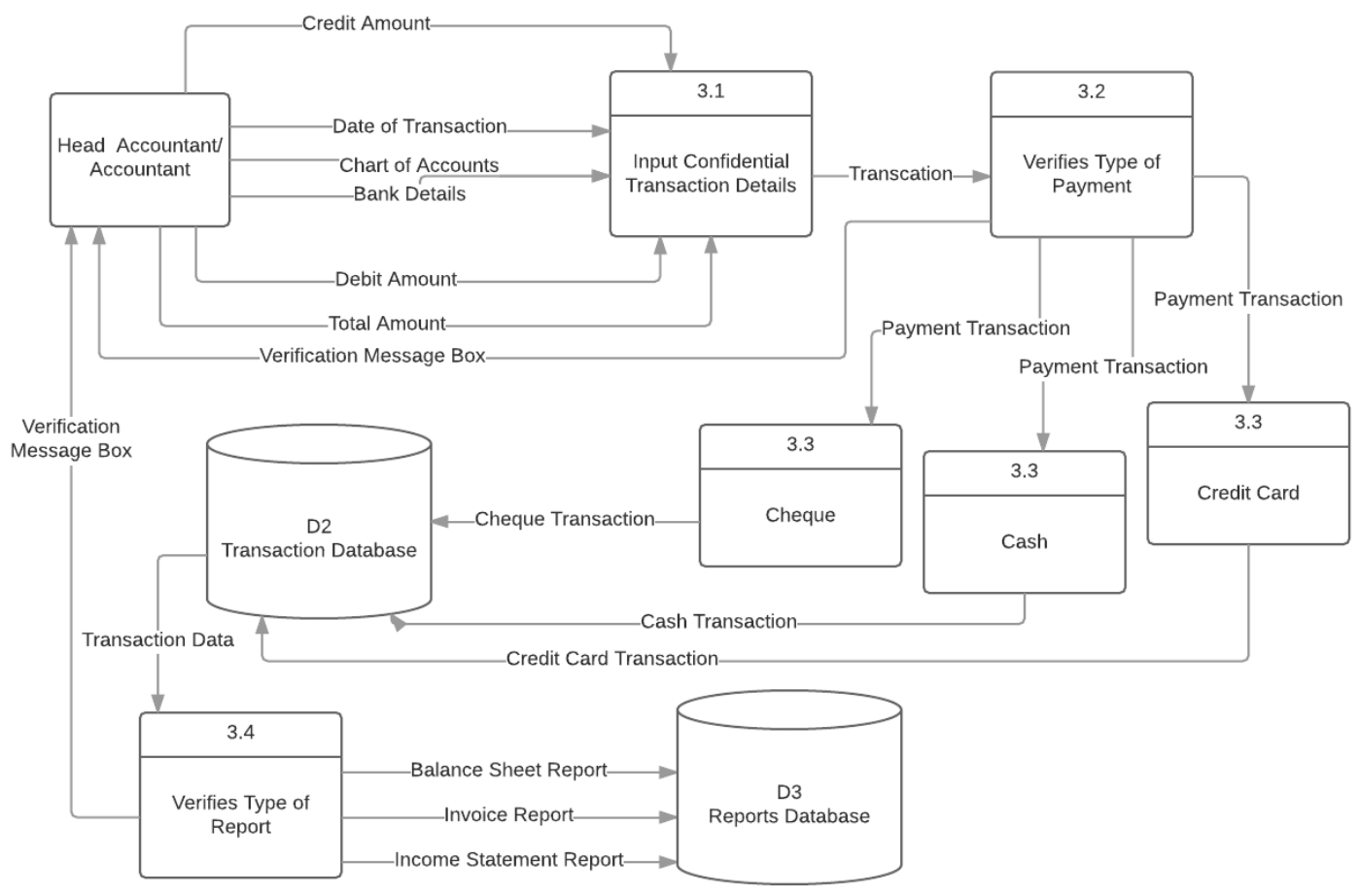

Figure 8. Data Flow Diagram: Level 1: Generate Report

\section{RESULTS AND DISCUSSION}

Authorized personnel can use the proposed system by accessing it from any of the desktops found in the company's premise. The computer should be connected to the network of the company to be able to access the system. The following are the internet browsers that authorized personnel can use: Mozilla Firefox version 53.0.2, Google Chrome version 60.0, Safari 5 version 5.1.7, and Edge version 40.15063. Only the employees of Company $A B C$ will be granted permission to login and utilize the system. Unauthorized access is restricted. The permissions given to each user determine what kind of functions they can use. As seen in Figure 9, the user needs to type in his username and password.

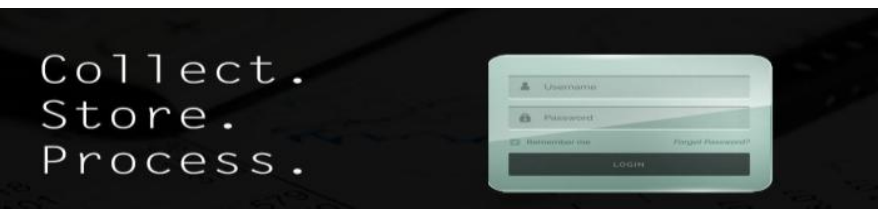

Figure 9. User Interface: Login Page 
As shown in Figure 10, when the user successfully logs in the account, he is redirected to a home page. In this case, it is the administrator's home page. He can see the functions that he can perform, such as Register Users, Add Transactions, and Generate Reports.

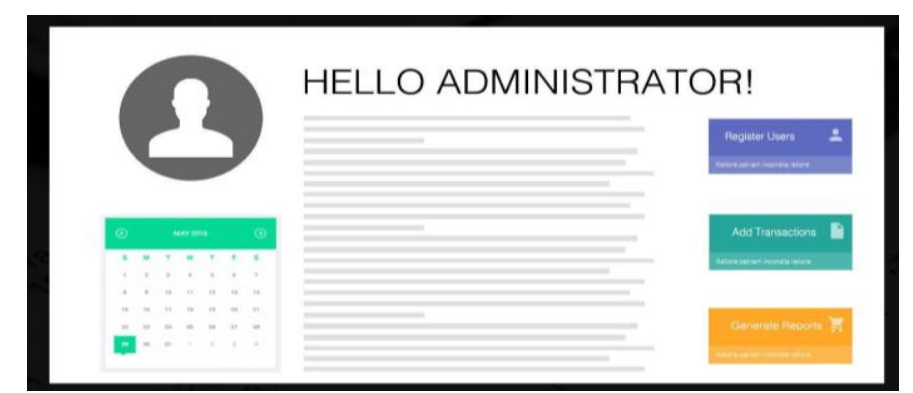

Figure 10. User Interface: Home Page for Administrator

Users who are given administrator privileges can add transactions. As shown in Figure 11, the user needs to supply data such as date, chart of accounts category, and amount. The system will not accept incorrect input such as negative amount and wrong date patterns. The user should also supply the type of payment done for the current transaction after pressing the next button. They may opt to choose among cash, card, and bank payment.

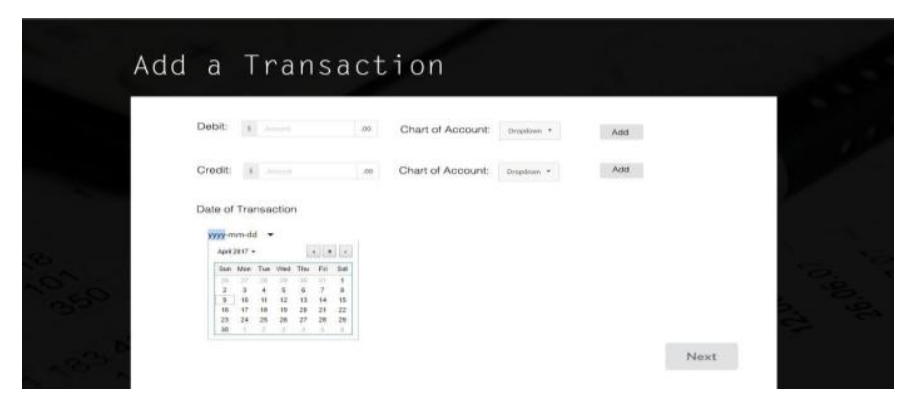

Figure 11. User Interface: Adding a Transaction

The user can request a report based on the given date. As seen in Figure 12, the user needs to specify the type of report and the date range he needs. The aggregate information in the reports came from the previously inputted financial transactions in the system. The user may also view previously requested financial reports such as Balance Sheet, Invoices (Figure 13), and Income Statement (Figure 14). The user can download and print the said report. 


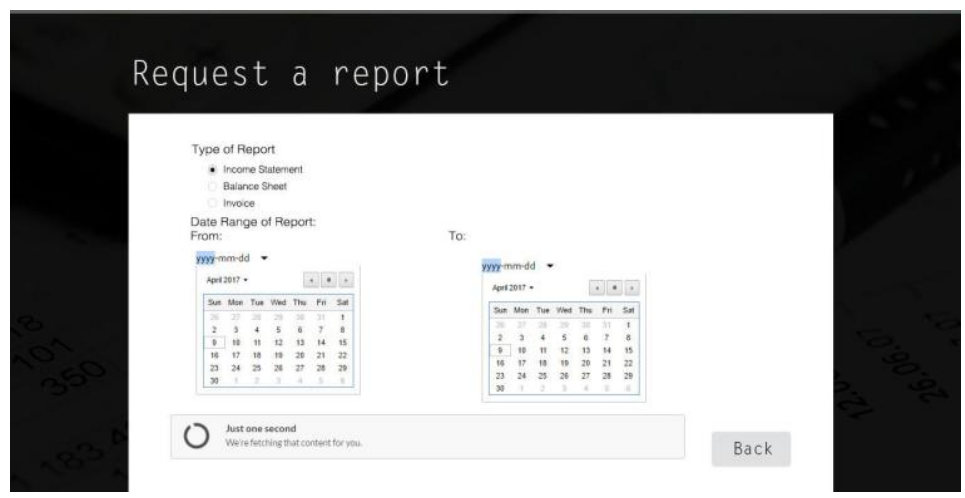

Figure 12. User Interface: Requesting Report

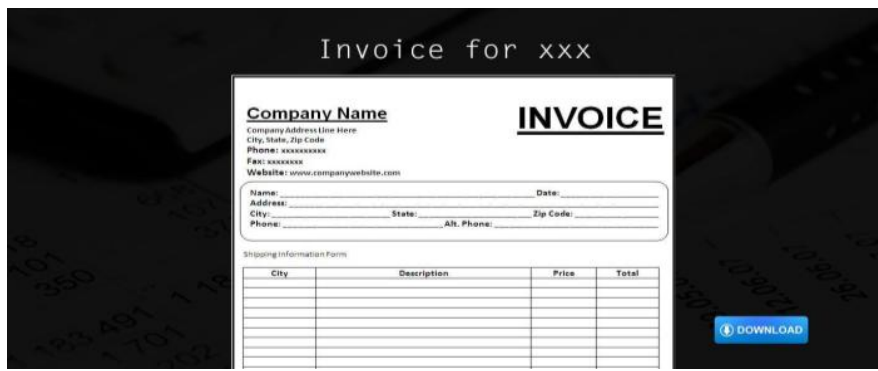

Figure 13. User Interface: Viewing of Report Generated - Invoice

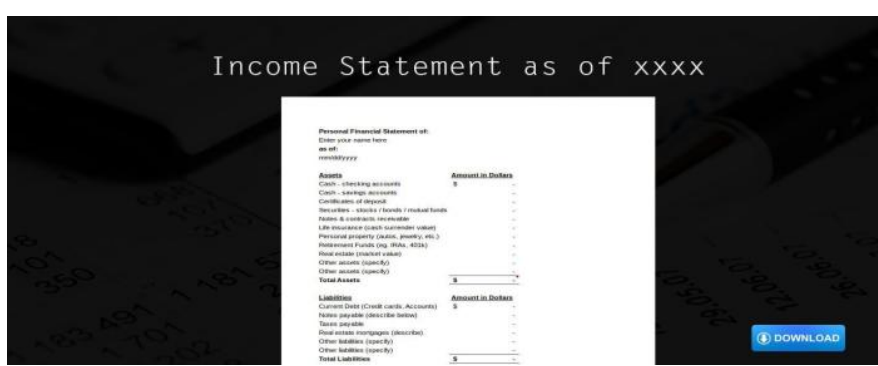

Figure 14. User Interface: Viewing of Report Generated - Income Statement

\section{CONCLUSIONS AND RECOMMENDATIONS}

The proposed Accounting Information System (AIS) aims to create an avenue for the Accounting Department that will increase productivity, and save time and energy. With the system, the employees can efficiently track all the transactions they need, as well. The system has a high impact on the company's performance for it shows the real-time status of the company's financial position to the stakeholders. The accountants will no longer have a difficult time in creating their reports manually; hence, the proposed system shall help the stakeholders of the company in making sound decisions for the company. 


\section{FUTURE WORKS}

The proposed Accounting Information System (AIS) will help eliminate the manual transactions of Company $A B C$. The researchers and programmers intend to develop the system using the proposed design. To improve its accessibility to its users, it is also recommended that a mobile version of the system that works both in Android and iOS platforms be developed.

\section{ACKNOWLEDGMENT}

The researchers would like to thank the University of Asia and the Pacific Department of Information Science and Technology for all the support in the research undertaking. Lastly, the researchers would like to praise God for his presence before, during and after the writing of this research paper and for all His guidance.

\section{REFERENCES}

Abduljalil, K., \& Zainuddin, Y. (2015). Intrinsic and extrinsic motivation as attitude factors towards adoption of accounting information system (AIS) in Libyan SMEs. International Journal of Academic Research in Accounting, Finance and Management Sciences, 5(1), 161-170. doi: 10.6007/IJARAFMS/v5-11/1553.

Akkermans, H. A., Bogerd, P., Yücesan, E., \& Van Wassenhove, L. N. (2003). The impact of ERP on supply chain management: Exploratory findings from a European delphi study. European Journal of Operational Research, 146(2), 284-301.

Del Rosario, E., Del Rosario, J., Nieva, M., Tan, T., \& Tangkeko, M. (2016). CollaboratelT: A CCS IT thesis portal with electronic document management system. Paper presented at the DLSU Research Congress 2016, De La Salle University, Manila, Philippines. Retrieved from http://www.dlsu.edu.ph/conferences/dlsu-research-congressproceedings/2016/HCT/HCT-II-01.pdf

Diavastisa, I., Anagnostopouloua, E., Drogalasa, G., \& Karagiorgosa, T. (2016). The interaction effect of accounting information systems user satisfaction and activitybased costing use on hotel financial performance: Evidence from Greece. interaction, 15(4), 757-784.

Grande, E. U., Estebanez, R. P., \& Colomina, C. M. (2011). The impact of accounting information systems (AIS) on performance measures: Empirical evidence in Spanish SMEs. International Journal of Digital Accounting Research, 11, 25-43.

Kendall, K., \& Kendall, J. (2011). System analysis and design (eighth edition). New Jersey: Pearson.

Mndzebele, N. (2013). The usage of accounting information systems for effective internal controls in the hotels. International Journal Advanced Computer Technology, 2(5), 1-3. 
Salehi, M., Rostami, V., \& Mogadam, A. (2010). Usefulness of accounting information system in emerging economy: Empirical evidence of Iran. International Journal of Economics and Finance, 2(2), 186-195. doi:10.5539/ijef. v2n2p186.

Spătărelu, I. \& Petec, D. (2015). The importance of accounting information in decision making. Retrieved from http://stec.univ-ovidius.ro/html/anale/RO/2016/2016-Ifull/Section-V/32.Spatarelu_lonut.pdf

Tang, A. (2015). Accounting information systems for mSME survivability. DLSU Business Notes and Briefings, 3(3), 1-4. Retrieved from http://www.dlsu.edu.ph/research/centers/cberd/pdf/cbrd-vol3-num3.pdf

TechTarget. (2017). Agile software development. Retrieved from http://searchsoftwarequality.techtarget.com/definition/agile-software-development

Tegarden, D., Wixom, B. H., \& Dennis, A. (2013). System analysis and design with UML (4th edition). New Jersey: Wiley.

Wang, D. H. M., \& Huynh, Q. L. (2013). Effects of environmental uncertainty on computerized accounting system adoption and firm performance. International Journal of Humanities and Applied Sciences, 2(1), 13-21. Retrieved from http://journalsweb.org/siteadmin/upload/37323\%20IJHAS021036.pdf.

Weygandt, J. J., Kieso, D. E., \& Kimmel, P. D. (2012). Accounting principles. Hoboken, NJ: John Wiley \& Sons. 